\title{
O manuseio de arma de fogo: estado da arte e perspectivas aplicadas na avaliação psicológica
}

\author{
Handling a firearm: State of the art and perspectives applied in psychological evaluation \\ Manejo de armas de fuego: Estado del arte y perspectivas aplicadas en la evaluación psicológica
}

Recebido: 01/02/2021 | Revisado: 05/02/2021 | Aceito: 11/02/2021 | Publicado: 15/02/2021

\author{
Astrid Sharon Pontes Hasbun \\ ORCID: https://orcid.org/0000-0002-3757-2841 \\ Laureate International Universities, Brasil \\ E-mail: astrid.sharon@gmail.com \\ Ionara Dantas Estevam \\ ORCID: https://orcid.org/0000-0002-4123-3244 \\ Laureate International Universities, Brasil \\ E-mail: ionaradantas@gmail.com \\ Nilton Soares Formiga \\ ORCID: https://orcid.org/0000-0003-4907-9736 \\ Laureate International Universities, Brasil \\ E-mail: nsformiga@yahoo.com
}

\begin{abstract}
Resumo
A violência tem feito parte da história da maioria dos lugares no mundo atualmente e o Brasil segue a mesma tendência. Essa realidade faz com que algumas pessoas procurem se armar por se sentirem inseguras e busquem a arma de fogo como uma forma de proteção. As legislações que regulamentam a área de armamento vêm ao longo dos anos buscando um maior controle, entretanto a partir de 2019 é possível perceber uma abertura e certo incentivo ao uso de armas de fogo. E embora o posicionamento sobre possuir uma arma como forma de garantir segurança traga divergência de opiniões, esse fato tem contribuído para o aumento da procura pela obtenção de registro e porte de arma de fogo no Brasil. Dentre as avaliações psicológicas compulsórias mais realizadas no Brasil está a avaliação psicológica para porte de arma que tem como finalidade verificar se a pessoa possui características compatíveis para o trabalho armado ou posse e manuseio de arma de fogo. Contudo, a área apresenta ainda muitas fragilidades como: estudos na área ainda são escassos, inexistência de instrumentos sugeridos pela Instrução normativa da Polícia Federal n $78 / 2014$ para avaliar determinados construtos psicológicos, capacitação dos profissionais para aplicação, correção e análise dos resultados, elaboração de documentos, remuneração e entrevista devolutiva ao candidato. É necessário que o profissional esteja devidamente capacitado, atualizado e aja dentro dos preceitos éticos elencados pela regulamentação da área para que suas conclusões sejam cientificamente embasadas e tragam segurança para a sua prática profissional.
\end{abstract}

Palavras-chave: Avaliação psicológica; Porte de arma de fogo; Avaliação psicológica para manuseio de arma de fogo.

\begin{abstract}
Violence has been part of the history of most places in the world today and Brazil follows the same trend. This reality makes some people try to arm themselves because they feel insecure and look for the firearm as a form of protection. The legislation that regulates the area of weaponry has come over the years seeking greater control, however from 2019 it is possible to perceive an opening and some incentive to the use of firearms. And although the position on possessing a weapon as a means of guaranteeing security brings diverging opinions, this fact has contributed to the increase in demand for registration and carrying a firearm in Brazil. Among the most common compulsory psychological evaluations carried out in Brazil is the psychological evaluation of the possession of a weapon, the purpose of which is to verify whether the person possesses compatible characteristics for armed work or possession and handling of a firearm. However, the area still presents many weaknesses such as: studies in the area are still scarce, non-existence of instruments suggested by the Normative Instruction of the Federal Police $\mathrm{n}^{\circ}$ 78/2014 to evaluate certain psychological constructs, qualification of professionals for application, correction and analysis of results, elaboration of documents, remuneration and devolutive interview to the candidate. It is necessary that the professional is properly trained, updated and act within the ethical precepts listed by the regulations of the area so that their conclusions are scientifically based and bring security to their professional practice.
\end{abstract}

Keywords: Psychological assessment; Firearm possession; Psychological assessment for firearm handling.

\section{Resumen}

La violencia ha sido parte de la historia de la mayoría de los lugares en el mundo actualmente y Brasil sigue la misma tendencia. Esa realidad hace que algunas personas busquen armarse por sentirse inseguras y busquen el arma de fuego como una forma de protección. Las legislaciones que regulan el área de armamento vienen a lo largo de los años 
buscando un mayor control, pero a partir de 2019 es posible percibir una apertura y cierto incentivo al uso de armas de fuego. Y aunque el posicionamiento sobre poseer un arma como forma de garantizar seguridad trae divergencia de opiniones, ese hecho ha contribuido al aumento de la demanda por la obtención de registro y porte de arma de fuego en Brasil. Entre las evaluaciones psicológicas obligatorias más realizadas en Brasil está la evaluación psicológica para porte de arma que tiene como finalidad verificar si la persona posee características compatibles para el trabajo armado o posesión y manejo de arma de fuego. Sin embargo, el área presenta todavía muchas debilidades como: estudios en el área aún son escasos, ausencia de instrumentos sugeridos por la Instrucción normativa de la Policía Federal n 78/2014 para evaluar ciertos constructos psicológicos, capacitación de los profesionales para aplicación, corrección y análisis de los resultados, elaboración de documentos, remuneración y entrevista devolutiva al candidato. Es necesario que el profesional esté debidamente capacitado, actualizado y actúe dentro de los preceptos éticos enumerados por la reglamentación del área para que sus conclusiones sean científicamente fundadas y aporten seguridad a su práctica profesional.

Palabras clave: Evaluación psicológica; Porte de armas de fuego; Evaluación psicológica para el manejo de armas de fuego.

\section{Introdução}

A violência tem feito parte da história da maioria dos lugares no mundo atualmente e o Brasil segue a mesma tendência. Segundo o Atlas da Violência divulgado pelo IPEA (Instituto de Pesquisa Econômica Aplicada) a taxa de homicídios por arma de fogo no Brasil subiu 15,4\% entre 2008 e 2018 passando de 34.147 para 41.179.

A publicação utiliza dados do sistema de informação de mortalidade do Ministério da Saúde e traz informações até 2018. Essa realidade faz com que algumas pessoas procurem se armar por se sentirem inseguras e busquem a arma de fogo como uma forma de proteção. Dessa forma, aumenta também a procura pela obtenção de registro e porte de arma de fogo no Brasil.

Segundo o 14 a Anuário Brasileiro de Segurança Pública (2020) em 2019 havia 1.056.670 registros de posse de arma ativos no Brasil com um forte aumento de 65,6\% de registros entre 2017 e 2019. Este anuário apresenta, ainda, alguns números preocupantes: das armas registradas, 6.740 foram extraviadas, perdidas, roubadas ou furtadas e havia 58.812 posses ou portes ilegais no país.

Entretanto, na contramão das pesquisas e evidências científicas que sugerem o controle responsável das armas, desde 2019 tem havido mudanças na legislação brasileira que traz flexibilizações no acesso da população às armas de fogo. Entre janeiro de 2019 e julho de 2020 foram editados, segundo o Atlas de violência (IPEA, 2020), onze decretos, uma lei e quinze portarias do exército que incentivam à disseminação das armas de fogo.

Todavia, ainda segundo o Atlas da violência de 2020, vários desses documentos foram revogados apontando para uma falta de reflexão e embasamento técnico para uma produção adequada de documentos e avaliação de impactos futuros que podem durar décadas (IPEA, 2020).

Entretanto, o posicionamento sobre possuir uma arma como forma de garantir segurança traz divergência de opiniões. Segundo Demarco e Balestrin (2019) essa divergência ocorre uma vez que nem todos acreditam no fato de que possuir uma arma trará mais segurança, pois na verdade acreditam que poderá trazer mais prejuízos já que seu uso inadequado pode acarretar resultados que não podem ser revertidos.

\section{Metodologia}

O presente trabalho trata-se de uma revisão integrativa de literatura que permite a análise de determinado assunto e possibilita a síntese de diversos estudos já publicados. Esta revisão foi operacionalizada de acordo com as seguintes etapas: identificação do tema, levantamento bibliográfico, seleção de textos e estruturação lógica do estudo. A pesquisa foi realizada através da análise de livros, artigos científicos, dissertações e teses disponíveis em repositórios digitais abertos à comunidade acadêmica, utilizando as seguintes plataformas: Biblioteca Virtual de Saúde, Pubmed, Scielo, PePsic e APA Psycnet. Foram usados os seguintes descritivos: "avaliação psicológica para porte de arma de fogo"; "avaliação psicológica para manuseio de 
arma de fogo"; "psychological evaluation for firearms" e "Evaluación psicológica en el uso de armas de fuego". Após a leitura e avaliação dos textos, foram selecionados os documentos de maior interesse do ponto de vista técnico-científico para complementar as discussões mais recentes da área de avaliação psicológica para manuseio de arma de fogo.

\section{Discussão}

Para Pirelli, Wechsler e Cramer (2015) ter uma arma de fogo em casa está associado a um aumento de risco de suicídio e homicídio por arma de fogo. Ainda de acordo com o 14 a Anuário Brasileiro de Segurança Pública (2020) um outro dado importante nesse cenário é que não há fronteiras entre as armas legais e as que alimentam a criminalidade, visto que muitas vezes a arma que foi comprada por um cidadão para defesa pessoal pode ser roubada, extraviada e estar envolvida tempos depois em um assalto ou até mesmo um homicídio. Em 2019 foram apreendidas 105.038 armas no país segundo o anuário.

Becerra e Bail Pupko (2016) assinalam que nos países com maior disponibilidade de armas há mais crimes violentos. E que para reduzir as mortes violentas é necessário políticas efetivas para o porte de armas. Se não é possível impedir o uso, por diversas razões, é imprescindível limitar a permissão aumentando a rigorosidade e exigência para esse tipo de habilitação.

Retomando o histórico sobre a legislação sobre posse e porte de armas no Brasil, em 1997 foi criada a Lei Federal $n^{\circ}$ 9.437/97 que institui o Sistema Nacional de Armas (SINARM), estabelece condições para o registro e para o porte de arma de fogo, define crimes e entre outras providências define critérios para o porte de arma por civis e torna obrigatória a comprovação de aptidão psicológica para o sujeito que deseja obter porte de arma de fogo. De acordo com Resende (2017) esta lei tinha como objetivo diminuir o número de ocorrências de má utilização de arma de fogo por pessoas despreparadas.

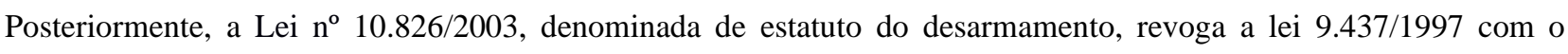
objetivo de manter um maior controle sobre as armas de fogo no Brasil. Werlang e Nascimento (2010) citam que a proposta preponderante desta Lei era o desarmamento do maior número possível da população e criar normas mais rígidas para a concessão do registro e porte de arma.

A referida lei apresenta importantes contribuições sobre a regulamentação para obtenção de registro e porte de arma de fogo tornando proibido o uso pela população, exceto pelos agentes de segurança e casos funcionais como agentes de inteligência, auditores fiscais e maiores de 25 anos desde que comprovem aptidão psicológica e motivação para ter uma arma (Brasil, 2003).

Nesse cenário, a comprovação de aptidão psicológica, com a finalidade de avaliar a estrutura da personalidade, tornou-se um dos requisitos necessários, para os sujeitos que desejam registrar uma arma ou para aqueles que necessitam do porte de arma. O decreto 5.123/2004 acrescenta em seu artigo 12, que o interessado em adquirir arma de fogo deve comprovar aptidão psicológica atestada em laudo conclusivo fornecido por psicólogo do quadro da Polícia Federal ou por ela credenciado (Brasil, 2004).

Em 2005 foi realizado um referendo no Brasil, no qual a população deveria responder a seguinte pergunta: "O comércio de armas de fogo e munição deve ser proibido no Brasil?”. O resultado do referendo foi que a população votou pela não proibição do comércio de armas e munição no país. Para Werlang e Nascimento (2010) esse resultado ocorreu em função da ideia de que as pessoas necessitam de armas para própria defesa uma vez que o Estado não é capaz de garantir uma segurança adequada à população e as armas são uteis para tal.

A partir da Lei $n^{\circ}$ 10.826/2003 e com o resultado do referendo, a concessão de registro e/ou porte de arma passou a ser concedido ao civil desde que ele apresente alguns requisitos estipulados pelos Decretos $n^{\circ} 5.123 / 2004$ e $n^{\circ} 6.715 / 2008$ : 
I - declarar efetiva necessidade;

II - ter no mínimo, vinte e cinco anos;

III - apresentar original e cópia, ou cópia autenticada, de documento de identidade pessoal;

IV - comprovar, em seu pedido de aquisição e em cada renovação do Certificado de Registro de Arma de Fogo (CRAF), idoneidade e inexistência de inquérito policial ou processo criminal, por meio de certidões de antecedentes criminais da Justiça Federal, Estadual, Militar e Eleitoral, que poderão ser fornecidas por meio eletrônico;

$\mathrm{V}$ - apresentar documento comprobatório de ocupação lícita e de residência certa;

VI - comprovar em seu pedido de aquisição e em cada renovação do CRAF, a capacidade técnica para o manuseio de arma de fogo;

VII - comprovar aptidão psicológica para o manuseio de arma de fogo, atestada por psicólogo do quadro da Polícia Federal ou, por esta, credenciado. (Lei n ${ }^{\circ} 10.826,2003$ )

De acordo com Faiad e Alves (2018) a avaliação psicológica compulsória é uma avaliação de caráter obrigatório quando o indivíduo deve realizá-la para atender alguma demanda legal ou cumprimento de alguma exigência normativa.

Dentre as avaliações psicológicas compulsórias mais realizadas no Brasil as autoras citam: avaliação para obtenção da Carteira Nacional de Habilitação (CNH) para motoristas, avaliação no contexto de Concursos Públicos e avaliação para Manuseio de Arma de Fogo. A avaliação psicológica compulsória é ferramenta fundamental para o cuidado e proteção do indivíduo e da sociedade (CFP 2019a). Elas acontecem no Brasil atualmente nestes e outros contextos e servem como base para a tomada de decisão dos profissionais psicólogos.

Como já citado, dentre as avaliações psicológicas compulsórias está a avaliação para manuseio de arma de fogo que de acordo com o Resende (2019) tem por finalidade verificar se a pessoa possui características compatíveis para o trabalho armado ou posse e manuseio de arma de fogo.

Para Resende (2019) esse processo pretende mais que predizer os riscos de sofrer ou causar acidentes ou conflitos, tem também a intenção de identificar quais construtos psicológicos são relevantes para um manejo adequado de uma arma de fogo.

Frente a falta de legislação para essa realidade, foi promulgada em 2008 a resolução CFP no 018/2008 que dispõe sobre a atuação do psicólogo na avaliação psicológica para manuseio de arma de fogo e dentre outras providências ressalta a importância do profissional credenciado pela Polícia Federal atentar para toda legislação profissional, Código de Ética e rigor técnico na administração dos instrumentos de avaliação psicológica, utilizando apenas aqueles com "parecer favorável" para uso segundo regulamentação do CFP.

A resolução versa ainda que o material técnico proveniente das avaliações para manuseio de arma de fogo deve ficar sob guarda do psicólogo durante 05 anos, mesma orientação dada pelo manual de elaboração de documentos em seu artigo 15 na resolução CFP 006/2019 (CFP, 2019c)

De acordo com as resoluções que regulamentam a profissão, qualquer psicólogo graduado e inscrito no conselho regional pode adquirir testes e realizar avaliações psicológicas desde que se sinta capacitado para tal. Mas o profissional que pretende realizar avaliação psicológica para manuseio de arma de fogo deve inicialmente solicitar credenciamento junto ao SINARM, apresentando a documentação necessária e listada na Instrução Normativa do Departamento de Polícia Federal (DPF) no 78/2014 (Brasil, 2014).

Segundo a referida instrução normativa o profissional deve ter pelo menos 02 anos de efetivo exercício da profissão e certificado que ateste sua aptidão para aplicação dos instrumentos psicológicos previstos nos incisos I e II do art. $5^{\circ}$ (testes expressivo e projetivo).

Atualmente estão cadastrados 2.581 profissionais psicólogos para a realização de avaliação psicológica para concessão de porte de arma de fogo, divididos entre os vários Estados. Em termos regionais estão cadastrados 200 psicólogos na Região Norte, 512 na Região Centro-Oeste, 459 na Região Nordeste, 668 na Região Sudeste e 742 na Região Sul (Polícia Federal, 2020). 
É possível perceber que a divisão de profissionais é desigual entre as Regiões e fica ainda mais acentuada quando comparada por Estados. O Estado com maior número de psicólogos cadastrados é o Rio Grande do Sul com 352 profissionais e o Estado com menor número é o Amazonas com 4 profissionais cadastrados.

Esse número não pode ser comparado com o número de inscritos nos CRPs uma vez que não há uma proporção entre eles. Segundo o CFP (2020) o Estado de São Paulo possui o maior número de psicólogos inscritos no País (108.449 profissionais), no entanto, está em $6^{\circ}$ lugar na quantidade de psicólogos cadastrados na Polícia Federal.

A instrução DPF n $n^{\circ}$ 78/2014 propõe ainda uma bateria de instrumentos de avaliação psicológica utilizados na aferição das características da personalidade e habilidades específicas e deve conter no mínimo: 01 teste de atenção (difusa e concentrada); 01 teste projetivo; 01 teste expressivo; 01 teste de memória e 01 entrevista semiestruturada. Importante salientar que não há uma determinação do teste que deverá ser utilizado pelo psicólogo o que possibilita que o profissional possa escolher dentre aqueles que tem maior habilidade e domínio técnico para trabalhar.

Um outro dado importante presente na IN DPF n $n^{\circ} 78 / 2014$ são os anexos V e VI que trazem os extratos dos indicadores - necessários e restritivos - do sujeito que deseja manusear ou portar arma de fogo e para vigilantes. Existe uma diferença de indicadores entre os dois públicos como é possível perceber nos Quadros 1 e 2. Para os vigilantes são listados indicadores como afetividade, concentração e percepção que não estão nos indicadores para pessoas que desejam adquirir uma arma de fogo.

Quadro 1: Indicadores psicológicos para portador de arma de fogo.

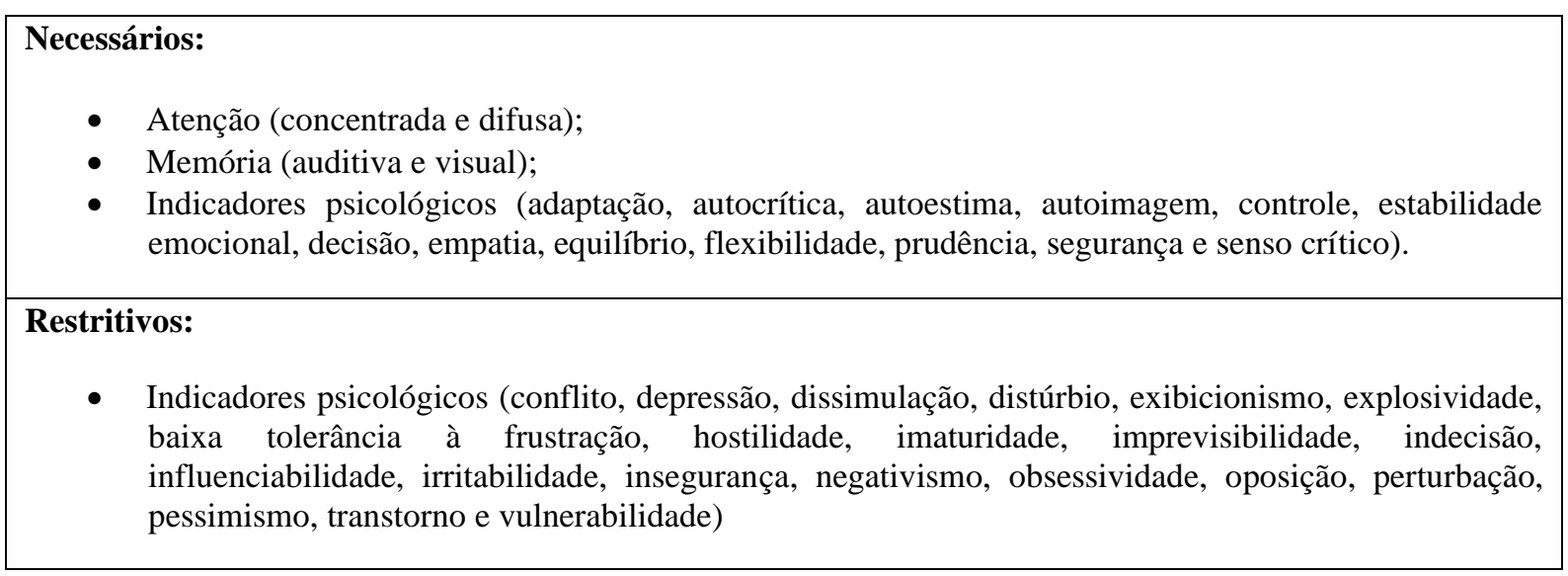

Fonte: Autores.

Quadro 2: Indicadores psicológicos para vigilante.

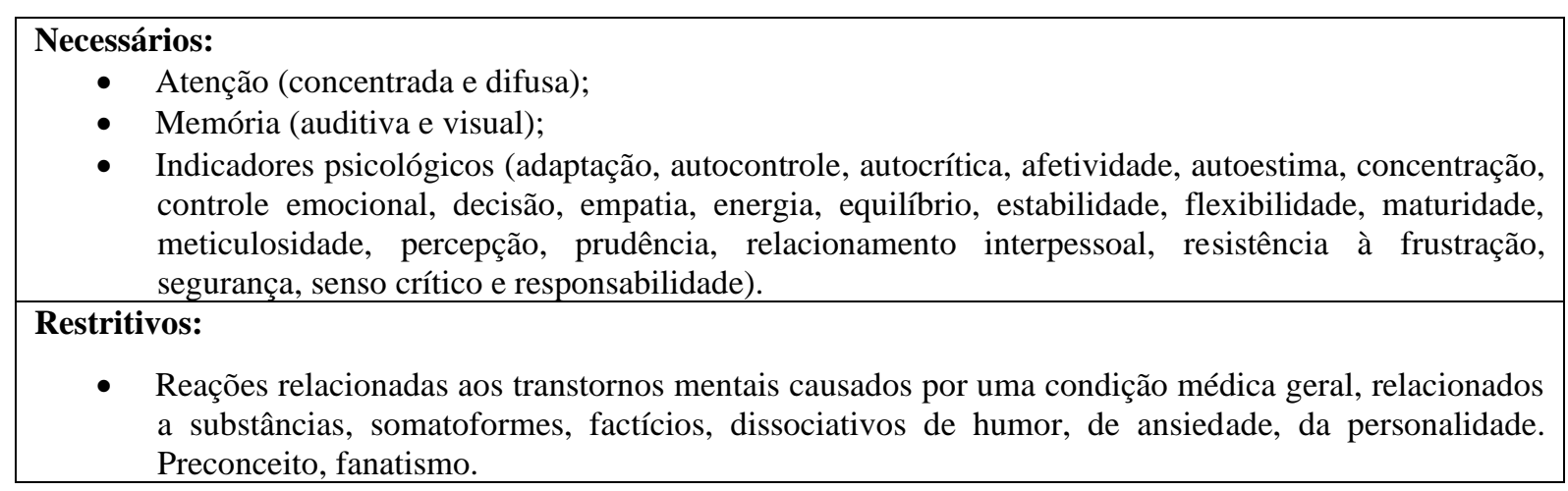


A partir de todas essas regulamentações para posse e porte de arma de fogo, a avaliação psicológica passa a assumir uma importância cada vez maior sobre a decisão do profissional psicólogo se o sujeito pode ou não portar uma arma de fogo. Entretanto, a escassez de instrumentos psicológicos específicos para a demanda tem dificultado a elaboração de um perfil psicológico adequado (Caneda \& Teodoro, 2010).

Com isso, é necessário que o profissional atente para a diferença apresentada nos quadros 1 e 2 entre os perfis necessários e restritivos para que possa selecionar os instrumentos de acordo com os indicadores que devem ser avaliados. Para além disso é importante que o profissional que realiza avaliações para manuseio de arma de fogo conheça os conceitos de cada indicador citado na resolução estando embasado na literatura técnica e científica para que possa identificá-los nos instrumentos utilizados na avaliação.

Em 2019 houve uma atualização da Lei n 10.826/2003 através do Decreto $n^{\text {o }}$ 9.847/2019 com o objetivo de estabelecer regras e procedimentos para a aquisição, o cadastro, o registro, o porte e a comercialização de armas de fogo e de munição e de dispor sobre a estruturação do SINARM e do Sistema de Gerenciamento Militar de Armas - SIGMA. Em seu artigo $12^{\circ}$, o referido decreto dispõe sobre os requisitos para quem tem interesse em registrar ou portar arma de fogo.

Todos os requisitos presentes no Decreto 5.123 estão presentes no novo decreto, com exceção a necessidade de declarar a efetiva necessidade de ter ou portar uma arma. Entretanto na Lei 10.826/2003 em seu artigo $4^{\circ}$ versa que para adquirir arma de fogo de uso permitido, o interessado deverá declarar a efetiva necessidade. Dessa forma é possível um questionamento: o Decreto $n^{\circ} 9.847 / 2019$ vai de encontro ao que está posto na Lei 10.826/2003, ou o Decreto tira a validade deste tópico da Lei a partir de sua publicação?

Embora exista legislação que regulamente a avaliação psicológica para manuseio de arma de fogo, a produção científica sobre o tema ainda é reduzida e não há pesquisas suficientes que possam traçar um perfil específico ou delimitar os instrumentos capazes de contribuir efetivamente com a avaliação para manuseio de arma de fogo. A consequência disso segundo Becerra e Bail Pupko (2016) é que por não haver consenso profissional sobre as características ou condições psicológicas que o sujeito deve apresentar para ser considerado apto a portar uma arma de fogo, a comprovação da aptidão pode variar de acordo com o profissional que fará a certificação não só em relação às variáveis psicológicas, mas também dos instrumentos utilizados para análise.

Para verificar a produção existente sobre o tema foi realizado um levantamento em janeiro de 2021 nas bases de dados Biblioteca Virtual de Saúde, Pubmed, Scielo, PePsic e APA Psycnet. Foram usados os seguintes descritivos: “avaliação psicológica para porte de arma de fogo"; "avaliação psicológica para manuseio de arma de fogo"; "psychological evaluation for firearms" e "Evaluación psicológica en el uso de armas de fuego".

Usando esses descritivos foi possível obter 26 referências publicadas entre os anos de 2002 e 2020 que foram categorizados por idioma e tipo de publicação. Sendo assim é possível verificar no quadro 3 que das 26 referências encontradas 21 são artigos, 03 são dissertações e 02 são teses. Dos artigos, 9 (43\%) estão em português, 7 em espanhol (33\%), 4 em inglês $(19 \%)$ e 1 em italiano (5\%). Se for levado em consideração a produção nos últimos 5 anos o número de referências cai para 10 publicações, sendo essas $70 \%$ em português, $20 \%$ em inglês e apenas $10 \%$ em espanhol. Em relação ao tipo de publicação nos últimos 5 anos, tem-se dez artigos e uma tese de doutorado.

Percebe-se assim que no período compreendido entre 2002 e 2020 maior parte das pesquisas realizadas na área foram publicadas em português e espanhol. Essa diferença pode se dar em função da diferença entre as leis dos países sobre a aquisição e registro de armas de fogo.

Na Itália, por exemplo, de acordo com Clerice et al (2016) a avaliação psicológica não é obrigatória no processo de obtenção de porte de arma, sendo realizado apenas um exame psicofísico por médicos (não necessariamente especialistas em 
saúde mental) e não por psicólogos. Nos Estados Unidos a avaliação só é exigida em alguns Estados como New Jersey (Pirelli et al 2015). Já na Argentina a avaliação psicológica é obrigatória assim como no Brasil.

Quadro 3: Descrição das publicações obtidas nas bases de dados analisadas.

\begin{tabular}{|c|c|c|c|}
\hline Ano & Título da publicação & Autoria & $\begin{array}{c}\text { Tipo de } \\
\text { publicação }\end{array}$ \\
\hline 2002 & $\begin{array}{l}\text { The evaluation of mental capability to use firearms: } \\
\text { practical and ethical questions }\end{array}$ & $\begin{array}{l}\text { Grinshpoon, A., Bauer, A. Mark } \\
\text { M. \& Mester, R. }\end{array}$ & Artigo \\
\hline 2002 & $\begin{array}{l}\text { Determinación de las variabiles psicológicas de } \\
\text { inadecuación para el uso de arma de fuego }\end{array}$ & Montes, J. N. & Artigo \\
\hline 2004 & $\begin{array}{l}\text { Secondary prevention for police officers involved in } \\
\text { job-related psychologically stressful or traumatic } \\
\text { situations }\end{array}$ & $\begin{array}{l}\text { Olaf, B., Gereon, H., Christoph, } \\
\text { P., Peter D. \& Udo W. }\end{array}$ & Artigo \\
\hline 2004 & $\begin{array}{l}\text { Evaluación de la impulsividad y riesgo en el uso de } \\
\text { armas de fuego en policías y fuerzas de seguridad }\end{array}$ & Pueyo, A. A. & Artigo \\
\hline 2004 & $\begin{array}{l}\text { Deontología de la peritación psicológica. El caso de } \\
\text { la evaluación para el uso de armas de fuego }\end{array}$ & Esparcia, A. J. & Artigo \\
\hline 2004 & $\begin{array}{c}\text { Notas sobre el marco legal de la evaluación de las } \\
\text { condiciones psicológicas para el uso de armas de } \\
\text { fuego en el ámbito civil y policial }\end{array}$ & Aguilar, M. G & Artigo \\
\hline 2006 & $\begin{array}{l}\text { Indicadores do Método de Rorschach para avaliação } \\
\text { da maturidade emocional para porte de arma de } \\
\text { fogo }\end{array}$ & Pellini, M.C & Tese \\
\hline 2007 & $\begin{array}{l}\text { Psicología y prevención de comportamientos de } \\
\text { riesgo. El caso de la tenencia y uso de armas de } \\
\text { fuego }\end{array}$ & Gil, F. T. \& Mollá, C. C. & Artigo \\
\hline 2008 & $\begin{array}{c}\text { Rischio di abuso di armi da fuoco: rassegna della } \\
\text { letteratura e proposte di procedure mediche di } \\
\text { prevenzione }\end{array}$ & $\begin{array}{l}\text { Clereci, di' Micheli, Veneroni, } \\
\text { Pirro \& Albassi }\end{array}$ & Artigo \\
\hline 2009 & $\begin{array}{l}\text { Desenvolvimento e propriedades psicométricas da } \\
\text { Escala Motivacional para o Porte de Arma (EMPA) }\end{array}$ & Caneda, C. R. & Dissertação \\
\hline 2010 & $\begin{array}{c}\text { Desenvolvimento e investigação de propriedades } \\
\text { psicométricas da escalamotivacional para porte de } \\
\text { arma (EMPA) }\end{array}$ & $\begin{array}{l}\text { Caneda, C. R. \& } \\
\text { Teodoro, M. L. }\end{array}$ & Artigo \\
\hline 2012 & $\begin{array}{l}\text { Contribuições da avaliação psicológica ao porte de } \\
\text { arma: uma revisão de estudos brasileiros }\end{array}$ & $\begin{array}{l}\text { Caneda, C. R. \& } \\
\text { Teodoro, M. L. }\end{array}$ & Artigo \\
\hline 2013 & $\begin{array}{l}\text { Evaluación de las competencias psicológicas de los } \\
\text { agentes de policía en el uso de armas de fuego }\end{array}$ & Dorta, A. V. & Dissertação \\
\hline 2014 & $\begin{array}{l}\text { Evaluación de las condiciones psicológicas para el } \\
\text { uso del arma de fuego en los cuerpos de seguridad }\end{array}$ & $\begin{array}{l}\text { Molas, J. V., Agusti G. M. \& } \\
\text { Sanosa, M. A. S. }\end{array}$ & Artigo \\
\hline 2014 & $\begin{array}{l}\text { Policiais e porte de arma de fogo através do teste } \\
\text { zulliger }\end{array}$ & Rodrigues, C. A. & Dissertação \\
\hline 2015 & Prática e Formação: Psicólogos na Peritagem em & Rafalski J. C. \& Andrade A. L. & Artigo \\
\hline
\end{tabular}


Research, Society and Development, v. 10, n. 2, e37610212538, 2021

(CC BY 4.0) | ISSN 2525-3409 | DOI: http://dx.doi.org/10.33448/rsd-v10i2.12538

\begin{tabular}{|c|c|c|c|}
\hline \multicolumn{3}{|c|}{ Porte de Arma de Fogo } & \multirow[b]{2}{*}{ Artigo } \\
\hline 2015 & $\begin{array}{l}\text { Psychological evaluations for firearm ownership: } \\
\text { Legal foundations, practice considerations, and a } \\
\text { conceptual framework }\end{array}$ & $\begin{array}{l}\text { Pirelli, G., Wechsler, H., \& } \\
\text { Cramer, R. J. }\end{array}$ & \\
\hline 2016 & $\begin{array}{c}\text { Escala de Atitudes frente à Arma de Fogo } \\
\text { (EAFAF): Evidências de Sua Adequação } \\
\text { Psicométrica }\end{array}$ & $\begin{array}{l}\text { Nascimento, T. G., Pimentel , C. } \\
\text { E. \& Castro, B. G. }\end{array}$ & Artigo \\
\hline 2016 & $\begin{array}{c}\text { O teste de Zulliger - estudo psicométrico para } \\
\text { concessão de arma de porte de arma de fogo e oara } \\
\text { normatização com adultos em Belo Horizonte (MG) }\end{array}$ & Resende, M. A. & Tese \\
\hline 2016 & $\begin{array}{c}\text { Aptitud psicofísica y ética para el uso o portación de } \\
\text { armas de fuego. Generación de un protocolo de } \\
\text { evaluación }\end{array}$ & Becerra, L. \& Bail, P. V. & Artigo \\
\hline 2017 & $\begin{array}{l}\text { Avaliação psicológica para manuseio de arma de } \\
\text { fogo: considerações críticas à IN-DPF } \mathrm{N}^{\circ} 78 \text { de } \\
10.02 .2014\end{array}$ & Maya, A. M. & Artigo \\
\hline 2018 & $\begin{array}{l}\text { Access to firearms: When and how do mental health } \\
\text { clients become prohibited from owning guns? }\end{array}$ & Barnhost, A. \& Kagawa, R. M. & Artigo \\
\hline 2018 & $\begin{array}{c}\text { Contribuições do Satepsi para Avaliações } \\
\text { Psicológicas Compulsórias (Trânsito, Porte de Arma } \\
\text { e Concursos Públicos) }\end{array}$ & Faiad, C. \& Alves, I. C. B. & Artigo \\
\hline 2019 & $\begin{array}{l}\text { Desafios da avaliação psicológica para porte de } \\
\text { arma de fogo }\end{array}$ & Resende, M. A. & Artigo \\
\hline 2019 & $\begin{array}{l}\text { Avaliação Psicológica para concessão do porte de } \\
\text { arma de fogo à população e policiais da PMMG }\end{array}$ & Resende, M. A. & Artigo \\
\hline 2020 & $\begin{array}{c}\text { Questionário Desiderativo atualizado como } \\
\text { instrumento da avaliação psicológica ao manuseio } \\
\text { de armas de fogo }\end{array}$ & Burani, G. A. \& Rodrigues, S. O. & Artigo \\
\hline
\end{tabular}

Fonte: Autores - Biblioteca Virtual de Saúde, Pubmed, Scielo, PePsic, APA, Psycnet.

Segundo Caneda e Teodoro (2012), a avaliação psicológica para manuseio de arma de fogo é marcada por dificuldades e limitações em sua fundamentação e exercício, existindo divergência de opiniões sobre sua validade em relação à segurança pública-privada.

A partir do Quadro 3 é possível inferir que se for realizado um recorte de tempo dos últimos cinco anos de publicação, há apenas 10 artigos e uma tese de doutorado, sendo destes $02 \mathrm{em}$ inglês, 01 em espanhol e 08 em português. Esse dado reflete a importância da realização de estudos e justifica, até certo ponto, as limitações encontradas na atuação profissional na área.

Resende (2019) cita alguns desafios encontrados pelos psicólogos como: credenciamento, escolha de instrumentos pertinentes à IN 78/2014, capacitação para aplicação, correção e análise dos resultados, elaboração de documentos, remuneração e entrevista devolutiva ao candidato.

Em relação aos indicadores apontados na IN 78/2014 não há um perfil específico. Quantos são necessários para que um candidato seja considerado apto ou inapto? Quanto da presença de um ou de outro construto de personalidade é suficiente para tornar uma pessoa apta ou inapta a manusear uma arma de fogo? Há uma quantidade mínima para a inaptidão? É essencial o investimento na elaboração de um perfil que possa nortear os profissionais psicólogos neste tipo de avaliação. 
A escolha dos testes deve ser feita com cautela e não se pode utilizar o resultado de um único teste como suficiente para emitir um parecer de aptidão psicológica. A IN 78/2014 sugere utilização de seis instrumentos já citados, mas não impede que o psicólogo utilize outras técnicas, como por exemplo teste de inteligência, se julgar necessário.

Nesse ponto é necessário falar da importância da entrevista no processo de avaliação, uma vez que servirá para contextualizar o histórico de vida e fornecer informações sobre o sujeito que está interessado em registrar ou portar arma. Segundo Demarco e Balestrin (2019) o sujeito pode tentar omitir ou distorcer alguma informação comprometedora e nesse sentido, os testes psicológicos são necessários para complementar as informações coletadas no processo de avaliação subsidiando o parecer final com informações baseadas em instrumentos com embasamento científico.

Pirelli et al (2015) afirmam que alguns aspectos devem ser abordados para avaliação do risco de futura violência para si e para os outros como histórico de envolvimento em danos pessoais ou a terceiros (por exemplo, o motivo da busca pela licença, experiência e planos para o uso e armazenamento da arma de fogo, planos para desenvolver maior competência e educação continuada em relação ao uso e segurança de armas de fogo).

Para Pellegrino (2015) na entrevista é preciso realizar uma análise atenta das condições psíquicas atuais, mas também da situação pregressa para que seja possível ter um quadro clínico completo. Ainda no que se refere aos instrumentos, a bateria sugerida pela PF tem instrumentos aprovados pelo SATEPSI que atendam a necessidade desse tipo de avaliação? Por exemplo, como avaliar a memória auditiva? Este indicador aparece como necessário nos anexos da IN 78/2014.

Em pesquisa no SATEPSI, em janeiro de 2021, não foi verificado nenhum instrumento favorável que atenda a esse tipo de avaliação. Maya (2017) reforça ainda que na referida instrução não fica claro que tipo de memória deve ser avaliada, se a curto ou longo prazo, ficando a cargo do profissional psicólogo essa interpretação.

A falta da devida capacitação dos profissionais para aplicação, correção, interpretação e análise dos dados de uma avaliação psicológica é um dos principais problemas encontrados na área, entretanto, é necessário sinalizar que além da deficiência dos cursos de graduação, alguns profissionais não seguem, por exemplo, o que está previsto no manual do teste e realizam uma correção superficial, também conhecida como “olhômetro". Isso acontece muitas vezes em virtude do volume de aplicações que o profissional realiza. Algumas clínicas que trabalham com avaliações para vigilantes costumam fazer esse tipo de correção no teste palográfico (isto é, trata-se de um teste que avalia as principais características da personalidade por meio do comportamento expressivo).

A elaboração de laudos é outro ponto de atenção. Neste aspecto é necessário atentar para o fato que a IN 78/2014 sugere um modelo de laudo que deve ser emitido pelo psicólogo após a realização da avaliação psicológica. No entanto, a resolução CFP 006/2019 em seu artigo $10^{\circ}$ afirma que nos processos de avaliação psicológica compulsória, o documento a ser emitido pela(o) psicóloga(o) deverá ser o atestado psicológico. E que quando solicitado, o psicólogo pode emitir um laudo além do atestado (CFP, 2019c. p. 11).

Em se tratando da estrutura do documento, o modelo sugerido na IN 78/2014 traz 4 itens a saber: a) identificação da clínica, identificação do avaliado, condição de apto ou inapto e identificação do profissional psicólogo.

Entretanto, a estrutura de laudo apresentada pelo CFP na resolução 006/2019 traz os seguintes itens: a) identificação, descrição da demanda, procedimento, análise, conclusão e referências. É importante destacar que no item procedimento, a resolução deixa claro que o profissional psicólogo deve apresentar o raciocínio e os recursos técnico-científicos, especificando o referencial teórico metodológico que fundamentou suas análises, interpretações e conclusões. Ou seja, não se trata de somente dizer se o sujeito está apto ou inapto. Sendo assim, é possível um questionamento: o modelo sugerido pela IN 78/2014 como laudo está de acordo com o a resolução CFP 006/2019? 
A remuneração também se apresenta como um desafio uma vez que a IN 78/2014 estipula que o psicológico credenciado não pode cobrar valor que exceda o valor médio dos honorários profissionais cobrados para realização de avaliação psicológica para o manuseio de arma de fogo constante da tabela do Conselho Federal de Psicologia.

De acordo com essa tabela (CFP, 2019b) o valor médio para esse tipo de avaliação é de R \$496,07. Entretanto, o valor médio praticado pelos profissionais da área está bem abaixo desse valor. Segundo Resende (2019) a média praticada é de $\mathrm{R} \$ 200,00$ a $\mathrm{R} \$ 250,00$ e não é raro encontrar valores ainda mais baixos, em torno de $\mathrm{R} \$ 80,00$.

Esse valor pode ser encontrado em clínicas que realizam a aplicação coletiva e assim "ganham" em cima do volume de avaliações realizadas. Esse tipo de prática abre espaço para que as avaliações sejam realizadas com padrões mínimos de exigência, menos consistentes e muitas vezes em desacordo com o prescrito pela PF e CFP.

A entrevista devolutiva traz questionamentos por parte dos psicólogos que trabalham com avaliação para manuseio de arma de fogo. Segundo o CFP (2019c, p.20) “para entrega do relatório e laudo psicológico, é dever da(o) psicóloga(o) realizar ao menos uma entrevista devolutiva à pessoa, grupo, instituição atendida ou responsáveis legais”.

O questionamento é sobre o risco que se corre na devolutiva de sujeitos que foram considerados inaptos na avaliação psicológica uma vez que esses candidatos muitas vezes não aceitam os resultados e chegam a ameaçar ou tentar subornar o psicólogo. Alguns desses sujeitos estabelecem a relação de consumidor e acreditam que porque pagaram o serviço devem ser considerados aptos.

Dessa forma, o psicólogo deve manter uma postura ética e cautelosa para fazer esse sujeito entender os motivos da contra indicação naquele momento, e que isso não impede que no futuro possa ser realizada uma nova avaliação e ele possa, então, ser considerado apto.

É necessário, portanto, que os psicólogos reflitam sistematicamente sobre essa prática avaliativa, uma vez que a população está exposta ao crescimento íngreme dos níveis de violência por arma de fogo. Armar ou desarmar alguém é de extrema responsabilidade e relevância social. Corre-se o risco de entregar uma arma a alguém incapaz de manter a sua própria segurança ou de outros ou de lidar de forma adequada com situações inesperadas podendo causar danos irreparáveis.

Um exemplo da concepção exposta acima, pode ser atribuído aos crimes que são divulgados nos noticiários locais e nacionais, diariamente, por exemplo: crimes passionais, atiradores, mulheres que matam por vingança, filhos que matam pais e suicídios entre profissionais de mão armada.

A partir de uma avaliação psicológica bem estruturada, consistente e embasada cientificamente é possível distinguir os que estão aptos dos que não estão e conceder armas somente para aqueles que apresentam requisitos para tal. De acordo com Clerici et al (2016) uma avaliação eficaz compreende os aspectos de diagnóstico de quaisquer condições psicopatológicas em andamento e prognósticos, para a prevenção de comportamentos lesivos mesmo que a longo prazo.

É, portanto, dever do psicólogo dar um parecer de aptidão para o sujeito que demonstrou condições psicológicas para o manuseio de arma de fogo, bem como negar àqueles que não apresentem tais condições. Isso só é possível se o profissional estiver devidamente capacitado, atualizado e agir dentro dos preceitos éticos elencados pela regulamentação da área.

Desta forma há muito o que avançar nas pesquisas na área para que seja possível traçar um perfil específico de construtos necessários e restritivos. Pirelli et al (2015) apontam que é necessário investigar resultados como negligência no manuseio, armazenamento e uso de armas de fogo, e não apenas violência e resultados relacionados a suicídio e homicídio. Resende (2017) ressalta ainda a necessidade de pesquisas que diferenciem aspectos que podem ser específicos a uma determinada classe como civis, caçadores, atiradores esportivos, seguranças e policiais. Se faz necessário investir no desenvolvimento de estudos que investiguem a validade e fidedignidade dos instrumentos utilizados para que seja possível definir quais instrumentos de fato são eficazes para esse tipo de avaliação compulsória e porque não falar sobre a construção de instrumentos específicos para essa demanda. 


\section{Considerações Finais}

O presente artigo teve como objetivo demonstrar que embora a avaliação psicológica para porte de arma seja uma exigência legal no Brasil, há muitas questões a serem discutidas e poucas produções e estudos científicos que embasem as atividades realizadas pelos profissionais psicólogos.

Esse fato traz a necessidade de que todos os profissionais que atuam na área tenham a consciência de sua responsabilidade ao emitir um atestado de aptidão para um sujeito que se submeteu ao processo avaliativo para concessão de porte de arma de fogo.

O CFP junto à Polícia Federal vem ao longo dos anos buscando aprimorar o processo através de documentos regulatórios e mudanças na bateria de testes, mas isso não é suficiente. Um exemplo disso são os indicadores necessários e restritivos. Não há pesquisas suficientes que sustentem afirmar o quanto de cada indicador é ou não necessário para que um candidato seja considerado apto ou inapto.

Entretanto ainda há muitas limitações na área que precisam ser repensadas como não existir todos os instrumentos necessários para atender os requisitos sugeridos pela Polícia Federal, a falta de capacitação de vários profissionais para atuar na área e a estrutura do laudo ser diferente do regulamentado pelo CFP.

Dessa forma, para que tenhamos uma melhor atuação e maior respaldo técnico e ético, faz-se necessário desenvolvimento de estudos na área que investiguem a validade e fidedignidade dos instrumentos utilizados, e possibilitem a elaboração de um perfil do candidato, ou ainda um protocolo de padronização que possa dar maior segurança ao profissional que atua na área dada a responsabilidade e repercussão social desta atuação.

Dentre os construtos avaliados para manuseio de arma de fogo a personalidade é uma grande referência para avaliar o fenômeno neste tipo de avaliação. E como sugestão de estudos futuros seria interessante a realização de pesquisas que façam a associação do tema avaliação para porte de arma com o estudo da personalidade.

É preciso, para finalizar, reforçar que essa tomada de decisão por parte do profissional psicólogo deve ser pautada no rigor ético e técnico pois de sua decisão uma arma de fogo poderá passar de um instrumento de defesa e de proteção para um risco de vida de quem a manuseia ou dos que com ele convivem.

\section{Referências}

Becerra, L \& Bail Pupko, V. (2016) Aptitud psicofísica y ética para el uso o portación de armas de fuego. Genereción de um protocolo de evaluación. In XIV Congresso Argentino de Psicologia: "Psicologia y compromisso social”. Ciudad Autónoma de Buenos Aires. Federación de Psicólogos de la República Argentina, 2016. https://www.yumpu.com/es/document/view/55704067/libro-digital-del-xvi-congreso-argentino-de-psicologia

Brasil (1197). Lei 9.437, de 20 de fevereiro de 1997. Institui o Sistema Nacional de Armas - SINARM, estabelece condições para o registro e para o porte de arma de fogo, define crimes e dá outras providências. Publicada em 21 de fevereiro de 1964 . Diário Oficial da União. https://www.planalto.gov.br/ccivil_03/leis/19437.htm

Brasil (2003). Lei 10.826, de 23 de dezembro de 2003. Estatuto do desarmamento. Dispõe sobre registro, posse e comercialização de armas de fogo e munição, sobre o Sistema Nacional de Armas - SINARM, define crimes e dá outras providências. Publicada em 23 de dezembro de 2003 . Diário Oficial da União. Recuperado de http://www.planalto.gov.br/cciviL_03/leis/2003/L10.826.htm\#art36

Brasil (2004). Decreto 5.123, de 01 de julho de 2004. Regulamenta a Lei $\mathrm{n}^{\circ} 10.826$, de 22 de dezembro de 2003 , que dispõe sobre registro, posse e comercialização de armas de fogo e munição, sobre o Sistema Nacional de Armas - SINARM e define crimes. Publicado em 02 de julho de 2004 . Diário Oficial da União. http://www.planalto.gov.br/ccivil_03/_Ato2004-2006/2004/Decreto/D5123.htm

Brasil (2008). Decreto 6.715, de 29 de dezembro de 2008. Altera o Decreto ${ }^{\circ} 5.123$, de $1^{\circ}$ de julho de 2004, que regulamenta a Lei ${ }^{\circ} 10.826$, de 22 de dezembro de 2003, que dispõe sobre registro, posse e comercialização de armas de fogo e munição, sobre o Sistema Nacional de Armas - SINARM e define crimes. Publicado em 29 de dezembro de 2008. Diário Oficial da União. http://www.planalto.gov.br/ccivil_03/_Ato2007-2010/2008/Decreto/D6715.htm

Brasil (2008). Lei 11.706, de 19 de junho de 2008. Altera e acresce dispositivos à Lei n ${ }^{\circ} 10.826$, de 22 de dezembro de 2003 , que dispõe sobre registro, posse e comercialização de armas de fogo e munição e sobre o Sistema Nacional de Armas - Sinarm e define crimes. Publicada em 20 de junho de 2008 . Diário Oficial da União. http://www.planalto.gov.br/cciviL_03/_Ato2007-2010/2008/Lei/L11706.htm\#art1

Brasil (2019). Decreto 9.847, de 25 de junho de 2019. Regulamenta a Lei nº 10.826, de 22 de dezembro de 2003, para dispor sobre a aquisição, o cadastro, o registro, o porte e a comercialização de armas de fogo e de munição e sobre o Sistema Nacional de Armas e o Sistema de Gerenciamento Militar de Armas. Publicado em 25 de junho de 2019. Diário Oficial da União. http://www.planalto.gov.br/ccivil_03/_Ato2019-2022/2019/Decreto/D9847.htm\#art60 
Brasil, Polícia Federal (2014). Instrução normativa no.78/2014-DG/DPF de 10 de fevereiro de 2014. Estabelece procedimentos para o credenciamento e fiscalização de psicólogos responsáveis pela expedição de comprovante de aptidão psicológica para o manuseio de arma de fogo e regulamenta a atuação do psicólogo na avaliação psicológica do vigilante. http://www.pf.gov.br/servicos-pf/armas/credenciamento-psicologos/psicologos-crediciados/IN\%20782014.docx/view

Caneda, C. R. G., \& Teodoro, M. L. M. (2010). Desenvolvimento e investigação de propriedades psicométricas da escala motivacional para porte de arma (EMPA). Avaliação Psicológica, 9(3), 471-478. http://pepsic.bvsalud.org/scielo.php?script=sci_arttext\&pid=S1677-04712010000300013\&lng=pt\&tlng=pt.

Caneda, C. R. G., \& Teodoro, M. L. M. (2012) Contribuições da avaliação psicológica ao porte de arma: uma revisão de estudos brasileiros. Aletheia, (3839), 162-172. http://pepsic.bvsalud.org/scielo.php?script=sci_arttext\&pid=S1413-03942012000200013\&lng=pt\&tlng=pt.

Clerice, C. A., Veneroni, L., \& Invernizzi, R. (2006) La valutazione dell'idoneità psichica e dei fattori di rischio nella detenzione e il porto di armi da fuoco: una revisione della letteratura e osservazioni sull'attuale situazione italiana. Psichiatria e psicoterapia, 25:3, 226-239. https://www.earmi.it/varie/clerici\%20$\% 20 I d o n e i t \% \mathrm{C} 3 \%$ A0\%20psichica.pdf

Conselho Federal de Psicologia (2008). Resolução no 018. Brasília, DF. https://site.cfp.org.br/wp-content/uploads/2008/12/resolucao2008_18.pdf.

Conselho Federal de Psicologia (2019a). Os cenários que levaram à criação do SATEPSI. Revista diálogos. Avaliação psicológica: área em expansão. Ano 15, $\mathrm{n}^{\circ}$ 10. https://site.cfp.org.br/publicacoes/revistas-dialogos/

Conselho Federal de Psicologia (2019b). Tabela de honorários das (os) psicólogas (os). https://site.cfp.org.br/wpcontent/uploads/2019/08/sindpsi_fenapsi_tabela_atualizada_junho_2019_5.pdf

Conselho Federal de Psicologia (2019c). Resolução $n^{o}$ 006. Brasília, DF. https://atosoficiais.com.br/lei/elaboracao-de-documentos-escritos-produzidos-pelopsicologo-decorrentes-de-avaliacao-psicologica-cfp?origin=instituicao

Conselho Federal de Psicologia (2020). Infográfico. http://www2.cfp.org.br/infografico/quantos-somos/

DeMarco, T. T., \& Balestrin, J. L. (2019). Avaliação psicológica para porte de arma de fogo. Anuário Pesquisa E Extensão Unoesc Videira, 4, e23436. https://portalperiodicos.unoesc.edu.br/apeuv/article/view/23436

Faiad, C., \& Alves, I. C. B. (2018) Contribuições do Satepsi para avaliações psicológicas compulsórias. (Trânsito, porte de armas e concursos públicos). Psicologia: ciência e profissão, 38 (n.spe), 50-59. https://doi.org/10.1590/1982-3703000208851

Fórum Brasileiro de Segurança Pública. (2020) Anuário brasileiro de segurança pública 2019. Edição 13. https://forumseguranca.org.br/wpcontent/uploads/2019/10/Anuario-2019-FINAL_21.10.19.pdf

Itália (1998). Ministero dela sanita. Decreto legislativo 143, del 28 aprile 1998. Requisiti psicofisici minimi per il rilascio ed il rinnovo dell'autorizzazione al porto di fucile per uso di caccia e al porto d'armi per uso difesa personale. Pubblicato il 22 de Junho 1998. Gazzetta Ufficiale dela repubblica italiana. https://www.gazzettaufficiale.it/eli/gu/1998/06/22/143/sg/pdf

Maya, A. S. (2017). Avaliação psicológica para manuseio de arma de fogo: considerações críticas à IN-DPF No 78 de 10.02.2014. Especialize, Goiania, 14(01). https://www.ipog.edu.br/revista-especialize-online/edicao-n14-2017/avaliacao-psicologica-para-manuseio-de-arma-de-fogo-consideracoes-criticas-ain-dpf-n-78-de-10-02-2014/

Pellegrino, F. (2015) Valutazione clinica per il porto d'armi. Medicina e Doctor, Ano XXII, número 4, 42- 45. http://www.passonieditore.it/md.html

Pirelli, G., Wechsler, H., \& Cramer, R. J. (2015). Psychological Evaluations for Firearm Ownership: Legal Foundations, Practice Considerations, and a Conceptual Framework. Professional Psychology: Research and Practice. Advance online publication. http://dx.doi.org/10.1037/pro0000023

Rafalski, J. C., \& Andrade, A. L. (2015). Prática e Formação: Psicólogos na Peritagem em Porte de Arma de Fogo. Psicol. cienc. prof., Brasília, 35(2), 599612. http://www.scielo.br/scielo.php?script=sci_arttext\&pid=S1414-98932015000200599\&Ing=en\&ntm=iso

Resende, M. A. (2017). Avaliação psicológica para concessão do porte de arma de fogo à população e policiais da PMMG. Psicologia e saúde mental. 3(6), 113-131. http://revista.policiamilitar.mg.gov.br/periodicos/index.php/psicologia/article/view/97/195

Resende, M. A. (2019). Desafios da avaliação psicológica para porte de arma de fogo. Revista Psicologia e suas conexões.1(2). http://revistaadmmade.estacio.br/index.php/psicologiaesuasconexoes/article/viewPDFInterstitial/6681/47965702

Werlang, B. S. G., \& Nascimento, R. S. G. (2010). Avaliação psicológica para concessão de registro elou porte de arma de fogo. In: Avaliação psicológica: diretrizes na regulamentação da profissão. Brasília: CFP. 